\title{
RESPONSE OF VARIOUS PROMISING LINES OF UPLAND RED RICE TO DIFFERENT LEVELS OF WATERING AND DOSES OF P FERTILIZER
}

\author{
Nurlaili Ida, Student \\ Master's Program in Management of Dryland Resources, Postgraduate Program, \\ University of Mataram, Indonesia \\ Wangiyana Wayan*, Kisman \\ Faculty of Agriculture, University of Mataram, Indonesia \\ *E-mail: w.wangiyana@unram.ac.id
}

\begin{abstract}
This research aimed to examine growth and yield responses of various promising lines of upland red rice to different doses of $P$ fertilizer and different levels of watering, by conducting pot experiment in a plastic house of the Faculty of Agriculture (University of Mataram), located in the experimental farm in Narmada, West Lombok, Indonesia. The experiment was designed according to Randomized Complete Block Design, consisting of three treatment factors, i.e. upland red rice genotypes (G1=M-G8; G2=M-G11; G3= M-G13; G4= M-G17); levels of watering $(\mathrm{W} 1=200$ and $\mathrm{W} 2=300 \mathrm{ml} /$ day); and doses of $P$ fertilizer $(P 0=0 ; P 1=100$; $\mathrm{P} 2=200 \mathrm{~kg} / \mathrm{ha}$ of SP-36 fertilizer). Each treatment combination was prepared in three blocks as the replicates grouped according to the different sources of the soil used to fill the pots. Results indicated levels of watering appears to have most dominant effects, in which the higher level of watering resulted in higher leaf number, panicle length, dry straw weight, filled grain number, and grain yield, but increasing $\mathrm{P}$ doses only increased plant height and grain yield, while genotypes were significantly different only in plant height, tiller number, panicle number and straw dry weight. Although both increased $P$ doses and watering levels increased grain yield of red rice, there was a strong indication that increased $P$ doses can increase grain yield only when level of watering is also increased, or vice versa.
\end{abstract}

\section{KEY WORDS}

Phosphate fertilizer, red rice, water, upland rice.

Rice is a very important food crop in Indonesia because $95 \%$ of the population consumes rice as the staple food [1]. The high percentage of rice consumption in Indonesia has increased along with increasing population growth, while rice production has declined. One of the causes of the decline in rice production is the decreasing availability of paddy fields in which the total area of paddy land of 7.75 million hectares in 2013 decreased to 7.1 million hectares in 2018. The total paddy harvested area also decreased to only 10.9 million hectares in 2018. The decrease in the total area of paddy fields is mostly caused by the landuse conversion from agriculture to non-agriculture uses [2].

Due to the decreasing areas of lowland rice fields, the efforts to increase rice production to meet domestic food demand in Indonesia will have to be directed to the development of rice production in dry land. There are large potentials for these efforts because of the large total area of dry land in Indonesia, i.e. 28,577,848 ha including cultivated and uncultivated land [3]. However, according to Sutoro and Samadiredja [4], dry land in Indonesia has major constraints namely low water availability, especially during the dry seasons, and low nutrient availability. Water availability is one of the main limiting factors in plant growth and development, especially for rice plants, so we need to develop droughttolerant rice, such as upland red rice. Increasing upland rice productivity can be done through plant breeding programs in order to obtain drought tolerant rice varieties such as drought-tolerant promising lines of upland red rice, as has been done by Aryana [5], resulting 
in 11 promising lines of red rice [6], from which some genotypes, such as G2 (A1) and G3 (A2), were found to have special adaptability in drought environments.

In addition to low water availability, low nutrient availability is also a major constraint in the development of upland rice production in dry land, especially the availability of phosphorus. According to Brady and Weil [7], phosphorus is a macro-essential nutrient that is needed by plants in large quantities. In addition, Suhartatik et al. [8] also indicated that phosphorus $(P)$ is an important nutrient for plants as an energy sources (ATP) that are required in metabolism processes. Phosphorus plays a role in a variety of vital processes, such as for growth and yield formation, and formation of saplings and plant roots. The total content of phosphorus in the soil is high, but phosphorus is difficult to dissolve in the soil, so to enable phosphorus to be taken up by plant roots needs water as a solvent and means of transfer of the nutrient from bulk soil or growing media to the roots. Therefore, the strategy to increase rice production in the future is to develop innovative production technology for upland rice, such as upland red rice, in dry land, and for that, it is necessary to test the promising lines of upland red rice for better adaptation on different levels of water supply and doses of $P$ fertilizer application.

This study aimed to examine whether there are differences in the responses of upland red rice lines to different levels of water supply and different doses of a P fertilizer (SP-36) in pot culture.

\section{MATERIALS AND METHODS OF RESEARCH}

In this research, the experimental method was applied, by conducting pot experiment in a plastic house built in the experimental farm of the Faculty of Agriculture, University of Mataram. The farm is located in Nyurlembang village, Narmada district (West Lombok, Indonesia).

The experiment was designed according to Radomized Complete Block Design, with three treatment factors, i.e. different genotypes $(\mathrm{G})$ of promising lines of upland red rice $(\mathrm{G} 1=$ M-G8, G2= M-G11, G3= M-G13, G4= M-G17); levels of watering $(\mathrm{W} 1=200, \mathrm{~W} 2=200 \mathrm{ml} / \mathrm{pot}$; $P$ fertilizer doses $(P 1=0, P 2=100, P 3=200 \mathrm{~kg} / \mathrm{ha} S P-36)$. Each treatment combination was replicated three times, each of which corresponded to different paddock of different cropping history, from which the soil used to fill the pots was taken. Therefore, there were 72 experimental units.

This experiment is a small part of a genotype response examining 30 genotypes of rice consisting of 23 promising lines of upland and amphibious red rice, their parents, and national varieties; therefore, soil for filling all pots could not be taken from one site due to small sizes of paddocks. Thus, the soils for filling those pots were taken from one location of the same soil type but different blocks of paddocks having different cropping history (i.e. cassava, maize, and peanut), so that the whole experiment was designed according to the Randomized Complete Block Design by assigning those different paddocks as the replicates or blocks. After those soils were air-dried, they were used to fill the plastic pots of $4.5 \mathrm{~L}$ capacity, and filled with $4 \mathrm{~kg}$ of air-dried field soil after being passed through soil sieve of 2 $\mathrm{mm}$ sieving mesh. Before planting, each pot was also filled with $400 \mathrm{~g}$ fresh soil taken from mungbean rhizosphere and $40 \mathrm{~g}$ Bokashi (EM-4 fermented cattle manure); and they were mixed with the field soil around the center of soil surface in the pot up to $10 \mathrm{~cm}$ depth. Before filling with those soils, the pots were side-puctured $1 \mathrm{~cm}$ above the base of the pots using soldering iron so that each pot had 4 side holes for drainage. After finished filling all pots with those soils and Bokashi, the soil mixture in the pot was watered up to slightly above the field capacity, and they were then allowed to drain to field capacity for two days until planting date. At planting, 4-5 pre-germinated seeds of those rice genotypes were burried at the center of soil surface in the pots at $2 \mathrm{~cm}$ depth, and then covered with soil in the pot.

After finished seeding, those pots were watered up to slightly above field capacity, and then allowed to drain for two days. Then, starting from 3 days after seeding (DAS), the watering treatments were started, by applying two levels of watering treaments, i.e. $A 1=200$ $\mathrm{ml} /$ pot and $\mathrm{A} 2=300 \mathrm{ml} /$ pot for each watering or daily. However, approaching the end of the 
vegetative growth stage, the frequency of watering had to be increased, but the amount of water applied in each watering was maintained according to the watering treatments. At 7 DAS, thining was done to allow only two seedlings to grow per pot, and fertilization was done using a mixture of Urea $(45 \% \mathrm{~N})$, SP-36 $\left(36 \% \mathrm{P}_{2} \mathrm{O}_{5}\right), \mathrm{KCl}\left(60 \% \mathrm{~K}_{2} \mathrm{O}\right)$ fertilizers. According to the local recommendation for rice, Urea of $300 \mathrm{~kg} / \mathrm{ha}$ (or $1.2 \mathrm{~g} / \mathrm{pot}$ ) should be applied 3 times at $100 \mathrm{~kg} / \mathrm{ha}$ (or $0.4 \mathrm{~g} / \mathrm{pot}$ ) each (as basal fertilizer, 30 and $50 \mathrm{DAS}$ ), while SP-36 (according to treatment doses, i.e. $100 \mathrm{~kg} / \mathrm{ha}$ or $0.4 \mathrm{~g} / \mathrm{pot}$ and $200 \mathrm{~kg} / \mathrm{ha}$ or $0.8 \mathrm{~g} / \mathrm{pot}$, but the recommendation was $150 \mathrm{~kg} / \mathrm{ha}$ ) and $\mathrm{KCl}(150 \mathrm{~kg} / \mathrm{ha}$ or $0.6 \mathrm{~g} / \mathrm{pot})$ were applied once as basal fertilizer, which in this experiment they were applied at 7 DAS. The basal fertilizers at each dose were dibbled $7 \mathrm{~cm}$ beside the young rice plants at $7 \mathrm{~cm}$ depth; they were then covered with soil in the pot. The second and third application of Urea were done at $100 \mathrm{~kg} / \mathrm{ha}$ or $0.4 \mathrm{~g} / \mathrm{pot}$, by dibbling the fertilizer by the same way of dibbling the basal fertilizers.

Harvest of those upland red rice lines was done at 110 DAS, by cutting the clump just above the surface of the soil in the pots, to be able for measuring the weight of the dry straw and dry grains.

Observation varibles were plant height, tiller number, and leaf number at 8 weeks after seeding (WAS), as well as panicle length, weight of dry straw, panicle number per pot, percentage of unfilled grain number, filled grain weight per pot, and weight of 100 grains after harvest. Data were analyzed with Analysis of Variance (ANOVA) and the Least Significant Difference (LSD) at $5 \%$ level of significance, using the statistical software CoStat for Windows ver. 6.303 .

\section{RESULTS AND DISCUSSION}

The ANOVA results summarized in Table 1 show that there are no significant interaction effects between thre treatment factors in affecting growth and yield components of the upland red rice tested. However there are some significant main effects of individual factor, but among those factors, levels of watering appears to have most dominant effects, in which the higher level of watering resulted in significantly higher leaf number, panicle length, dry straw weight, filled grain number, and grain yield per pot. Different $P$ doses also had significant effects, but only on plant height and grain yield per pot, while the differences between genotypes tested were significant only in plant height, tiller number, panicle number and straw dry weight per pot.

Table 1 - Summary of ANOVA results on the effects of genotypes, P-fertilizer doses, and levels of watering on growth and yield components of promising lines of upland red rice in pot culture

\begin{tabular}{|c|c|c|c|c|c|c|c|c|}
\hline Observation variables & Blocks & Genotype & $\mathrm{P}$ doses & Water & $G * P$ & $G^{*} W$ & $P^{*} W$ & $G^{*} P^{*} W$ \\
\hline Plant height & ns & * & * & ns & ns & ns & ns & ns \\
\hline Tiller number & ns & * & ns & ns & ns & ns & ns & ns \\
\hline Leaf number & ns & ns & ns & * & ns & ns & ns & ns \\
\hline Panicle length & $\star \star *$ & ns & ns & * & ns & ns & ns & ns \\
\hline Straw dry weight & $* * *$ & *** & ns & ** & ns & ns & ns & ns \\
\hline Panicle number & ns & ** & ns & ns & ns & ns & ns & ns \\
\hline$\%$-unfilled grain number & ns & ns & ns & ns & ns & ns & ns & ns \\
\hline Filled grain number & ns & ns & ns & * & ns & ns & ns & ns \\
\hline Grain yield per pot & ns & ns & * & * & ns & ns & ns & ns \\
\hline Weight of 100 grains & * & ns & ns & ns & ns & ns & ns & ns \\
\hline
\end{tabular}

Note: $n s=$ non-significant; ${ }^{*} ;{ }^{* *} ;{ }^{* * *}=$ significant at $p<0.05 ; p<0.01 ; p<0.001$, respectively.

Looking at the differences in mean values of growth variables between genotypes (Table 2), it appears that the genotype M-G13 was the tallest and significantly taller that MG8, but on the contrary, the genotype M-G8 were highest in tiller number, leaf number, and straw dry weight per pot (Table 2), as well as in panicle number per pot (Table 3). Unfortunately, those highest means were not converted into highest grain yield per pot. This was most probably due to the highest mean of percentage of unfilled grain number $(43.49 \%)$ in the M-G8 (Table 3), so that its highest mean in panicle number per pot could not be 
converted into the highest mean in grain yield per pot (Table 3). In terms of differences in plant height between those genotypes, it could be due to their genetic differences, as stated by Sikuku et al. [9], that differences in plant height is a genetic character of each variety.

Table 2 - Mean plant height, tiller number, leaf number, panicle length, and dry straw weight per pot for each level of treatment factor

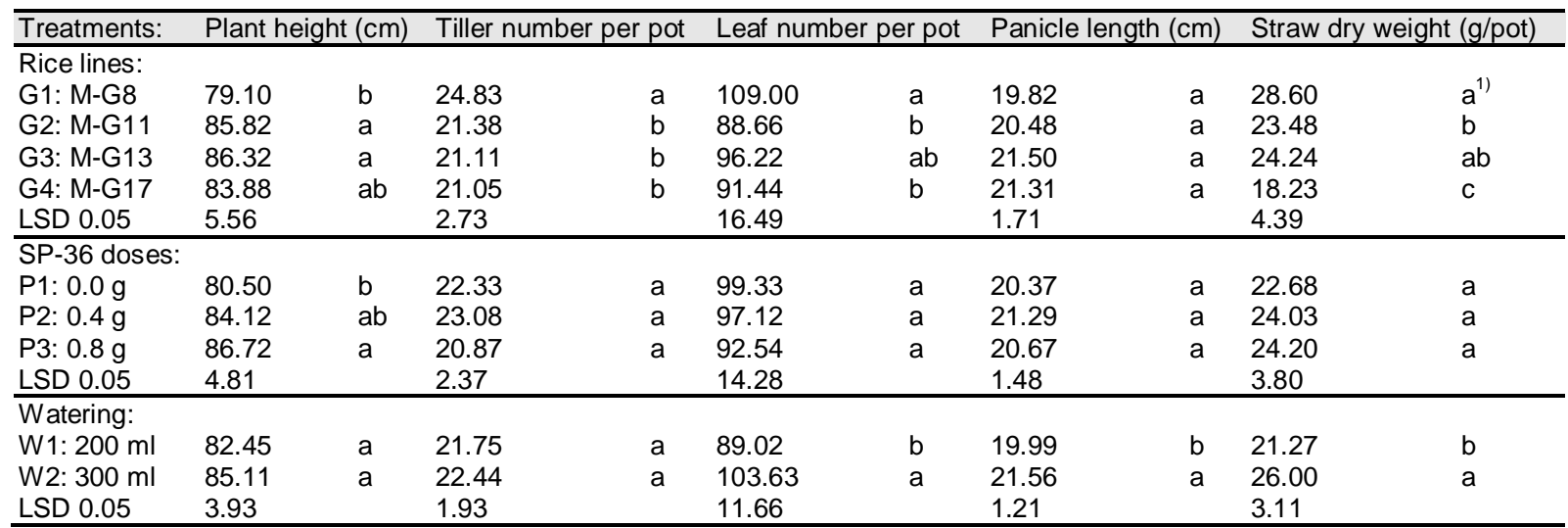

1) Mean values in each column followed by the same letters are not significantly different between levels of each treatment factor based on LSD test.

Table 3 - Mean panicle number, filled grain number, percentage of unfilled grain number, grain yield per pot, and weight of 100 filled grains for each level of treatment factor

\begin{tabular}{|c|c|c|c|c|c|c|c|c|c|}
\hline Treatments: & $\begin{array}{l}\text { Panicle number } \\
\text { pot }\end{array}$ & $\begin{array}{l}\text { per Filled grain } \\
\text { pot }\end{array}$ & number & $\begin{array}{c}\text { per } \% \text {-Unfilled } \\
\text { number }\end{array}$ & & $\begin{array}{l}\text { Grain } \\
\text { (g/pot) }\end{array}$ & & $\begin{array}{l}\text { Weight of } \\
\text { grains }\end{array}$ & 100 filled \\
\hline \multicolumn{10}{|l|}{ Galur: } \\
\hline G1: M-G8 & 14.88 & 394.05 & & 43.49 & $a$ & 10.41 & a & 2.71 & $a^{1)}$ \\
\hline G2: M-G11 & 12.16 & 401.38 & & 39.45 & a & 10.09 & a & 2.59 & $\mathrm{a}$ \\
\hline G3: M-G13 & 12.05 & 474.72 & & 39.26 & a & 12.09 & a & 2.59 & a \\
\hline G4: M-G17 & 10.11 & 389.33 & & 37.21 & a & 9.67 & a & 2.48 & a \\
\hline LSD 0.05 & 2.53 & 111.79 & & 10.92 & & 2.67 & & 0.29 & \\
\hline
\end{tabular}

\begin{tabular}{|c|c|c|c|c|c|c|c|c|c|c|}
\hline \multicolumn{11}{|l|}{ SP-36. } \\
\hline P1: $0.0 \mathrm{~g}$ & 12.41 & a & 379.37 & a & 42.19 & a & 9.28 & $b$ & 2.49 & a \\
\hline $\mathrm{P} 2: 0.4 \mathrm{~g}$ & 11.83 & a & 416.50 & a & 40.62 & a & 10.40 & $a b$ & 2.57 & a \\
\hline P3: $0.8 \mathrm{~g}$ & 12.66 & a & 448.75 & a & 36.75 & a & 12.01 & $\mathrm{a}$ & 2.71 & a \\
\hline LSD 0.05 & 2.19 & & 96.81 & & 9.46 & & 2.31 & & 0.25 & \\
\hline \multicolumn{11}{|l|}{ Watering: } \\
\hline $\mathrm{W} 1: 200 \mathrm{ml}$ & 12.11 & a & 374.27 & $b$ & 41.99 & a & 9.46 & $b$ & 2.58 & a \\
\hline W2: $300 \mathrm{ml}$ & 12.50 & a & 455.47 & a & 37.72 & a & 11.67 & a & 2.60 & a \\
\hline LSD 0.05 & 1.78 & & 79.05 & & 7.72 & & 1.89 & & 0.20 & \\
\hline
\end{tabular}

${ }^{1)}$ Mean values in each column followed by the same letters are not significantly different between levels of each treatment factor based on LSD test.

The different doses of $\mathrm{P}$ fertilizer (SP-36) only resulted in significant differences in plant height (Table 2) and grain yield per pot (Table 3), in which the highest mean was found in the red rice plants fertilized with the highest dose of SP-36 fertilizer. It is also clear from those tables that increasing doses of $\mathrm{P}$ fertilizer significantly increased both plant height and grain yield per pot, although the significant difference was only between zero and the highest dose. According to Ginting et al. [10], phosphorus is needed for the metabolism of the plants in order to stimulate plant growth, strengthen the stems, and increase lodging resistance. Putra [11] also stated that the application of fertilizers, whether with different types or doses, will affect growth response of rice plants, especially in plant height. In relation to grain yield, the increasing mean of grain yield per pot resulted from increasing doses of $P$ fertilizer in Table 3 is in line with research by Zulputra et al. [12]. They stated that phosphorus is needed by plants as energy in the photosynthesis process to increase photosynthetic rates, and increased photosynthetic rates, especially during the reproductive phase, would increase the percentage of filled rice grains, which in turn would increase the weight of filled grains per pot. Vejchasarn et al. [13] stated that low phosphorus availability significantly reduce rice 
yield. They reported that shoot dry weight, tiller number, plant height, number of nodal roots and shoot phosphorus content were reduced under low phosphorus availability. Although tiller number per pot was not significantly reduced, results of this experiment show that lower dose of $P$ fertilizer had resulted in lower grain yield per pot (Table 3 ).

Among the treatment factors tested, levels of watering resulted in most significant effects on growth (Table 2), in which reduced level of watering significantly reduced leaf number per pot, average panicle length, and weight of dry straw per pot, as well as yield components (Table 3 ) of the promising lines of red rice, in which reduced level of watering significantly reduced filled grain number per pot and grain yield per pot. These indicate that the lower level of watering had resulted in some water stress on the rice plants, especially during the mid-day during which air temperature is normally high in a glasshouse or plastic house. Although reduced level of watering did not significantly increase percentage of unfilled grain number (Table 3), the data obtained in this research show that lower number of filled grains per pot is in line with lower average of panicle length and lower number of leaves measured at the end of the vegetative growth stage, i.e. 8 WAS (anthesis period was during the week 10 WAS), and these all may have resulted in the lower grain yield per pot under the lower level of watering, as shown in Table 3. Song et al. [14] also reported that lower level of irrigation, i.e. AWD30 (AWD= alternate wetting and drying) resulted in significantly lower panicle number per $\mathrm{m}^{2}$, percentage of filled grain number, and grain yield per $\mathrm{m}^{2}$ in all four varieties of rice tested, compared with under higher level of moisture in AWD15.

Although ANOVA results show no significant interaction effects between treatment factors (Table 1), in fact, there is a strong indication of interaction, especially between levels of watering and doses of $\mathrm{P}$ fertilizer, as shown in Fig.1 and, especially in Fig.2.

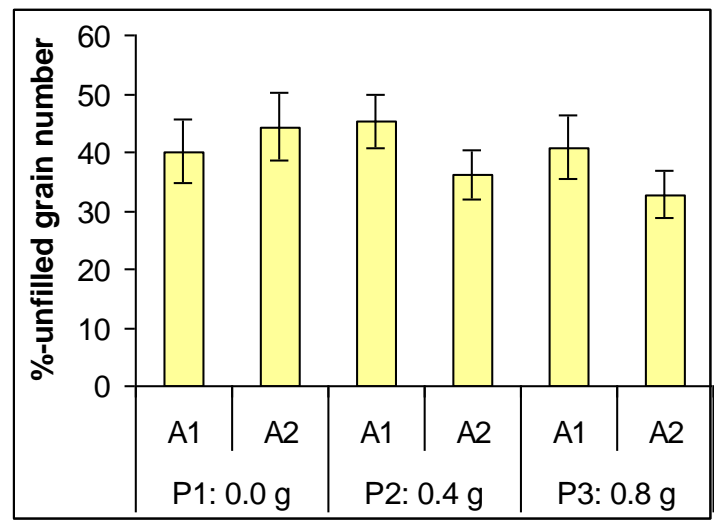

Figure 1 - Averages (Mean \pm SE) of \%-unfilled grain number as affected by interaction between watering levels and doses of $\mathrm{P}$ fertilizer (g/pot)

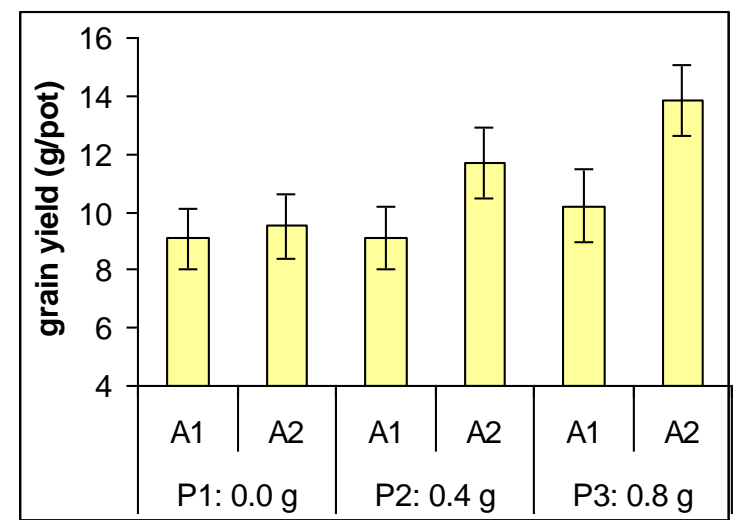

Figure 2 - Averages (Mean $\pm \mathrm{SE}$ ) of grain yield (g/pot) as affected by interaction between watering levels and doses of $P$ fertilizer ( $g / p o t)$

Although it was not significant, it can be seen from Fig.1 that the higher level of watering (A2) tended to decrease percentage of unfilled grain number on the red rice plants fertilized with SP-36 (the P fertilizer used in this experiment), but not on the rice plants receiving no $P$ fertilizer. However, these reduced percentages of unfilled grain number with increasing level of watering appeared to significantly increase grain yield per pot on the red rice plants receiving increased doses of $P$ fertilizer, but not on the rice plants receiving no $P$ fertilizer (Fig.2). Khalil and Yousef [15] also reported similar results from their experiment with Garden Cress plants, that due to the interaction effect, the maximum significant growth and yield components were in the plants grown under the highest soil moisture level (W3) inoculated with arbuscular mycorrhiza fungi and treated with the highest phosphorus level (P3). In addition, Shen et al. [16] stated that one unique characteristic of $P$ is its low availability due to slow diffusion and high fixation in soils. Therefore, the availability of soil moisture is one of the supporting conditions making soil $\mathrm{P}$ available for uptake by plant roots.

It can also be seen from Fig. 1 that even under the highest dose of $P$ fertilizer application, the percentage of unfilled grain number was still very high, i.e. more than $30 \%$; 
and this could be the main cause of the relatively low grain yield per pot, i.e. around the average of $14 \mathrm{~g} /$ pot or $3.5 \mathrm{t} / \mathrm{ha}$ maximum (Fig.2). So, although the fertilizer doses were based on 250000 clumps population per ha, it seems that the low volume of soil in the pot (less than $4.5 \mathrm{~L}$ per pot) could have limited the grain yield through the high percentage of unfilled grain number. Nevertheless, increasing doses of $P$ fertilizer coupled with higher level of watering has proven to be able to increase grain yield per pot when compared with no application of $P$ fertilizer in upland growing condition of red rice genotypes.

It can be seen from Table 1 that blocks had significant effects on panicle length, straw dry weight, and weight of 100 filled grains. This means that there were significant differences in these variables between soils of different blocks of paddocks having different cropping history, i.e. block \#1 was previously cropped with cassava, block \#2 was previously cropped with maize, and block \#3 was previously cropped with peanut. According to Arihara and Karasawa [17], cropping sequences could significantly affect $P$ availability in the soil through their effects on populations and development of arbuscular mycorrhizal fungi and their symbiosis with the crops in the sequences, as also reported by Karasawa et al. [18] that types of previous crops affect growth of maize under different soil moisture conditions. Therefore, when taking field soil for use as growing media in pot experiments, care needs to be taken for not to assume that they are homogenous even when they are mixed together.

\section{CONCLUSION}

It can be concluded that availability of both water and $\mathrm{P}$ significantly affect growth and grain yield of rice under upland growing conditions, and increasing doses of $P$ fertilizer to increase growth and grain yield will have to be followed by increasing availability of soil moisture, otherwise increasing doses of $P$ fertilizer may not be able to significantly increase grain yield of upland red rice.

\section{REFERENCES}

1. Norsalis, E. 2011. Upland and Paddy Rice. http://skp.unair.ac.id/repository/GuruIndonesia/Padigogodansawah_ekonorsalis_17170.pdf. Accessed: 30 January 2020.

2. Central Bureau 2018. https://www.bps.go.id/dynamictable/2019/04/15/1608/luas-panen-produksi-danproduktivitas-padi-menurut-provinsi-2018.html.

3. BalitbangTan. https:/Www.Researchgate.Net/Publication/323457112_Sumber_Daya

2018. Lahan_Pertanian_Indonesia_Luas_Penyebaran_Dan_Potensi_Ketersediaan.

4. Sutoro, I. and Samadiredja. 1989. Breeding reaction of maize and sorghum plants in vegetative growth stages. Penel. Palawija, 9(4): 146-151.

5. Aryana, I.G.P.M. 2009. Adaptation and Yield Stability of Promising Lines of Red Rice in Three Growing Environments. J. Agron. Indonesia, 37(2): 95 - 100.

6. Aryana, I.G.P.M., and W. Wangiyana. 2016. Yield Performance and Adaptation of Promising Amphibious Red Rice Lines on Six Growing Environments in Lombok, Indonesia. Agrivita, 38(1): 40-46.

7. Brady, N.C. and R.R. Weil. 2002. The Nature and Properties of Soils (13 ${ }^{\text {th }}$ edition), Prentice Hall, Upper Saddle River, NJ, USA.

8. Suhartatik, E., Abdullah, B., Sudarman, O., and Pulung. 2006. NPK fertilization on new type of rice. In: B. Suprihatmo, A. Gani, I.N. Widiarta and Hermanto (Eds.). Innovation in Rice Technology. Book 2, 339-352. Center for Food Crop Research and Development. Indonesian Ministry of Agriculture.

9. Sikuku, P.A., Kimani, J.M., Kamau, J.W., and Njinju, S. 2015. Evaluation of different improved upland rice varieties for low soil nitrogen adaptability. Int. J. Plant and Soil Science, 5(1): 40-49.

10. Ginting, R.C.B., Saraswati, R., and Husen, E. 2002. Phosphate Solubilizing Microorganisms. 
http://balittanah.litbang.deptan.go.id/dokumentasi/buku/pupuk/pupuk7.pdf (Accessed: 8 February, 2020).

11. Putra, S. 2012. Effect of NPK fertilizers in the form of single, compound and foliar fertilizers in increasing production of the upland rice Situ Patenggang. Agrotrop, 2(1): 55-61.

12. Zulputra, Wawan, and Nelvia. 2014. Response of upland rice (Oryza sativa L.) to application of Silicate and Phosphate fertilizers on Ultisol soil. Jurnal Agroekoteknologi, 4(2): 1-10. http://ejournal.uin-suska.ac.id/index.php/agroteknologi/article/view/1130/1023.

13. Vejchasarn, P., Lynch, J.P., and Brown, K.M. 2016. Genetic Variability in Phosphorus Responses of Rice Root Phenotypes. Rice, 9, 29 (2016). https://doi.org/10.1186/s12284016-0102-9.

14. Song, T., Xu, F., Yuan, W., Zhang, Y., Liu, T., Chen, M., Hu, Q., Tian, Y., Xu, W., and Zhang, J. 2018. Comparison on physiological adaptation and phosphorus use efficiency of upland rice and lowland rice under alternate wetting and drying irrigation. Plant Growth Regulation, https://doi.org/10.1007/s10725-018-0421-5.

15. Khalil, S.E., and Yousef, R.M.M. 2014. Interaction Effects of Different Soil Moisture levels, Arbuscular Mycorrhizal Fungi and Three Phosphate Levels on: I- Growth, Yield and Photosynthetic Activity of Garden Cress (Lepidium sativum L.) plant. International Journal of Advanced Research, 2(6): 723-737.

16. Shen, J., Yuan, L., Zhang, J., Li, H., Bai, Z., Chen, X., Zhang, W., and Zhang, F. 2011. Phosphorus Dynamics: From Soil to Plant. Plant Physiol., 156: 997-1005.

17. Arihara, J., and Karasawa, T. 2001. Phosphorus nutrition in cropping systems through arbuscular mycorrhizal management. p. 319-337. In: N. Ae, J. Arihara, K. Okada, and A. Srinivasan (Eds), Plant Nutrient Acquisition: New Perspectives. Tokyo, Japan: Springer-Verlag.

18. Karasawa, T., Arihara, J., and Kasahara, Y. 2000. Effects of previous crops on arbuscular mycorrhizal formation and growth of maize under various soil moisture conditions. Soil Sci. Plant Nutr., 46: 53-60. 